\title{
Eco Centricismis the Nucelus for Development: An Ecocritical of Amitav Ghosh's Hungry Tide
}

\author{
Ben J. Milton, J. Sundarsingh
}

\begin{abstract}
Ecocriticism facilitates understanding the complexities of relationship between man and nature as presented in literature. This relationship varies from one species to another and brings out the characteristics of nature and human being. India is a country rich in ecology and has its roots deeply dug in the environment. Hence it syncs well with the Environment. The Sundarbans is one such place which was is deeply immersed with the planet's ecology. AmitavGhosh, in his writing, has brought out the beauty of the place and has spoken about the life people lived over there. He has brought out nature and man from his perspective in an eco-centric world. He portrays the vicinity and talks about the relationship between the protagonist and nature in the novel Hungry Tide. Despite the various troubles that come their way their sole dependence upon nature is highlighted. The author points out the relevance and invariance of age that dependent upon nature which aspires to remain the same.
\end{abstract}

\section{INTRODUCTION}

Eco is a subset of biology, which is related to the connections between living beings in their common habitat and in addition their associations with that condition. The connection amongst man and nature isn't recently associated yet in addition interrelated. Ecocriticism emerged in William Rueckert's paper "Writing and Ecology: An Experiment in Ecocriticism. Ecocriticism talks about the various ideas and connections between man and the social construct at various level and exercised in writing. The trickery is at the logical level and different types of scholarly articulations. Individuals have a characteristic journey to discover their roots and be a piece of the regular habitat that they have a place with. Be that as it may, a similar time, they have over abused normal assets and misused nature to its fullest.

Ecocriticism deals with artistic feedback which claims to explore the correlation between writing and earth. It covers the investigation of writing, human studies, social science, brain research and so on and endeavours to consider the state of mind of humankind in environment. Notable names in this class include Eco poetics, nature writing and ecological artistic feedback. It thinks in what context the author has summoned enthusiasm for researchers around the world. Ecocriticism isn't just the utilization of environment and biological standards yet in addition the investigation of writing and hypothetical way to deal with the associations of the environment, culture and its intricacies. It is additionally an investigation of dialect through which writing is communicated. Writing famous for copying the

Revised Manuscript Received on 14 August, 2019.

Ben J. Milton, Ph.D. Research Scholar, Department of English, School of Science, Arts, Media and Management, Karunya Institute of Technology and Sciences, Coimbatore, Tamil Nadu, India.

Dr. J. Sundarsingh, Professor and Head, Department of English, School of Science, Arts, Media and Management, Karunya Institute of Technology and Sciences, Coimbatore, Tamil Nadu, India. contemporary issues couldn't have stayed untouched from this idea. This uprising danger to humankind from persistent abuse of our environment has grabbed the consideration of the journalists in later past. The textualization of previously mentioned ecological issues in scholarly works has offered ascend to another division of artistic hypothesis, to be specific ecocriticism.

Ecocriticism agrees with different branches of the ecological humanities, morals, history, religious examinations, human studies, humanistic geology in holding that natural marvels must be grasped, and that the present thriving exhibit of natural concerns must be tended to subjectively and additionally quantitative. At any rate as basic to their remediation as logical leaps forward and fortified administrations of strategy execution is the driving force of innovative creative ability, vision, will, and conviction. Without anyone else, innovative portrayals of ecological mischief are probably not going to free social orders from ways of life that de-pend on profoundly changing environments. Yet, pondering works of creative ability may incite increased worry about the outcomes of such decisions and conceivable other options to them.

\section{ECOCRITICISM IN INDIAN LITERATURE}

In the contemporary world, nature has been the centre in many noteworthy art works. Due to various developmental factors, there has been a lot of destruction in environmental landscape. The change in the social and economic situations of the world has totally changed the portrayals of man's disposition towards nature in scholarly articulations. Ecocriticism is a quickly extending zone of research covers extensive variety of writings and speculations which examine the relationship of man and nature. Ecological investigations in artistic messages through nature symbolism, sexual orientation develop, women's liberation, man-lady relationship, tourism, culture and so forth have more extensive implications than what is depicted through their exacting articulations. In Indian works in English too there are numerous abstract books that mirror the topic of ecocriticism in them. There are numerous ways that creators have investigated natural issues. In a few books it is integral to the book, while in others, it is optional to the story and different topics. There are a plethora of indian works which revolve around the environment thanks to the abundance of 
flora and fauna in the country. Despite direct correlation there is nature intertwined with the setting. The glorification of nature and description by writers gives gleam to the art work.

\section{ECOCENTRISM AND ECOCRITICAL ETHICS IN THE HUNGRY TIDE\& RESULTS}

Ecocentricism strives to establish an integrity between man and his society and to also to evolve to integrate a better society. Ecocenticism as a discipline attempts to register the fact that man is the reflection of ecology and he is the mere representation of ecology. The remedial aspects to redirect man from the existing unawareness is the prime objective of Ecocentricism. There is a demand which bases an ecocentric view is to break the inhumane and to raise a humane transition among the society. Ecocentricism promises effective solution through various integrated societal aspect.

AmitavGhosh's The Hungry Tide (2005) is one of the novels which has been written in the current era. In The Hungry Tide, Ghosh problematizes the strains between and inside human groups, their particular relations with the regular world, and the additional desultory reality of nature that progressions and is all the while changed by humankind. The novel revolves around the relationship between the marine biologist (Piyali Roy) and nature. Water is the creator of the relationships and the destroyer too. The bond is created when Piyali Roy almost drowns when she's aboard in a boat. Fokir rescues her from the water. It ends up becoming a beautiful relationship/friendship. It ends with his life being taken away when he tried to protect her. This ends the sad tale. Water here is the Alpha and the Omega in the relationship. Which talks about the role water plays in the lives of people.

The story entirely revolves around Sundarbans, which is one of the suburbs of India. Ghosh portrays the entire novel as the ecological witness in the region of west Bengal after 2004, which is completely surrounded by the mangrove forest. The characters employed in the novel intersect at various grounds and provide a striving purpose in illustrating the Ecological factors in novel. The narration has vividly explained the indispensable role of each aspect of nature such as crocodile, tiger, and various other animals in the entire story. The Characters and elements of nature have a wholesome part to justify environmental happenings and the course of change. The characters strive to ceaselessly explain and act as a bridge between the present and the past.

The beginning of the story is set on a train journey, where one of the protagonists, Kanai Dutt, a city based Translator, encounters another protagonist Piya, and he understands by her appearance to be a foreigner despite her Indian tone. The travellers are designated towards a same destination have a purpose to be accomplished, which is the central element of the plot. Kanai is translator from Delhi and he travels to Sundarbans to visit his aunt and get acquainted with the letter, which his dead uncle had left behind. Piya's purpose is revealed through the conversation, as she is returns to her native land from Seattle to find out about a rare species of Dolphin, as she works as a Marine Biologist. They depart at Lucibari after Kanai invites Piyal to his place as a nice gesture. He is accompanied by his aunt Nilima, and surprised to see the changeover of the entire place as he visits Lucbari after a long time. The water flow in the river has noticeably changed and also seems to be muddy.

Persuasively, Nilima made Kanai read the entire document, which was in the form of a hand written dairy. She insisted him to read the entire letter for the sake of Kusum, who is dead and an old friend of Kanai in Lusibari. The letter consists of the record of the main events that took place in the year 1979. Later on, Nilima narrates the entire happenings of Morichjhanpi massacre, where Kusum was killed. Nilima introduces Kanai to Fokir's family, and Fokir, son of Kusum, who is a local illiterate fisherman. Kanai comes to an understanding of how unsure the tide is in Sundarbans after he interacts with Fokir's wife Moyna. Meeting held in the hospital gave him a perspective, as thorough out the meeting Moyna was keen about sending their son Tutul to school. Moyna has deep objection towards her son to ride along her husband and she has plans for his son to attend school in the near future. Entire conversation doubtlessly enthralled Kanai, as he was clueless about the massacre and Fokir's family's plight. The narration gradually takes back to the memory of Kanai, when he met Kusum in the year 1970, and she was under Nilima's care as Kusam's family has broken apart. Kanai also reminisces the performance they watched together and the last time he saw Kusum.

Parallely, Piya has come to her native land to excavate a rare Dalphin species. Forest department of Sundarbans grants permission for her research and she seeks aid from the local fisherman. A forest guard offers to help her along with a boat pilot, Mejda. They set off for their destination into the woods and they reach a particular spot as Mejda proposes that they could spot the dolphin. Piya could realise after a while that these people are not helping and they are just condescending. The reckless attitude of the men intimidated her as she almost drowns into the water. She calls off the entire works as the men are not reliable to help her in anyways. However, in a meantime, Piya encounters Fokir before and they begin their persuit in the search of the dolphin to a place called Garjontola, where they encounter few Irrawaddy Dolphins around the area. Piya is overwhelmed as the day is not a failure and she could mark certain amount of progression in her work. Moreover, the genuineness of Fokir along with is son is an added factor in seamlessly pursue her work. However, the risk is like an inevitable factor as Piya almost lost her hand to crocodiles, which are also present in the water.

Piya then decides to seek help from kanai, who has already invited her to Lucibari. Nilima also offers to help Piya by allotting the guesthouse for Piya's stay during her time of research. Meanwhile, the narration takes the readers through the letter and details the meeting of Nirmal, Kusum and Nilima. Refuges of Morichjhapi were in a great distress due to various causes and also explained in the letter. Later, Piya along with Fakir and Kanai set off to Bhotbhoti to continue her study and Kanai decides to be as a translator between Fakir and Piya. Nilima shows her disapproval when

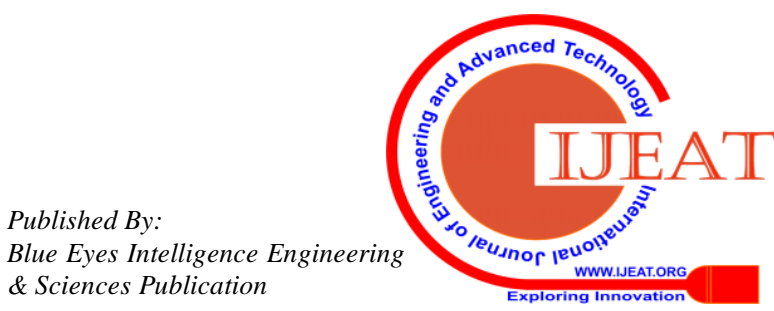


Kanai prepares to leave along with Piya, as tiger kills people every week in the place they are about to visit. This is a strong evidence that government priories tiger over common people and they are the actual victims. Further, they move towards the Garjontola pool in order to begin the research. Kanai beings to translate as Piya starts to talk about how she developed interest towards study of dolphins.

They encounter endless struggles throughout the stay in the pool. Kanai along with Horen decides to leave the place as Piya is able to communicate with Fokir better than the previous time. Kanai learns about a cyclone in the Garjontola pool later, but he was unable to return to the place and rescue them. Unfortunately, Fohir is hit by something large and he dies in the boat. Piya returns to Lucibari and narrates the whole incident to everyone. Piya also decides the name the project as Fokir.

The disposition of the characters in the novel has various factors that impedes their communication and nature acts as a driving force in order to unite them. Kanai's prime duty seems to act as a bridge between Piyali and Fokir, but there is a gradual progress in their relationship, where Piyali was able to comprehend the information communicated by Fokir. This stems up to the understanding of unity that nature has taught the characters in the novel. The portrayal of the character Fokir has also deepened the addition to the ecocentric narration of Ghosh. Fokir, the local fisherman, though kills animals for living also plays indispensable role in conserving them. Ghosh strives to give ecological solution to the central issue of the novel by effectively connecting past and present. The dramatic depletion of the nature is insisted as there is instinctive call of attention is portrayed through the character Kanai. Postcolonial emphasis also deliberately insists that ecological balance as Ghosh vividly describes the past and the need for the present change in the environment. Nalimia being the strongest postcolonial character proves to reinforce that human beings are part of nature and she resources to insist on saving animals and explains the danger of it. The strongest message of ecocentricism is conveyed through connecting indigenous people with their nature in which community based ecology is explained. Reconciling with nature is also strongly projected alongside of the entire story.

The grinding amongst arrive and the ocean in the Sundarbans makes a steady rubbing between the plant and creature life. Man's consistent infringement of the environments of the Sunderbans just legitimize the pressures between the different components of nature. The Hungry Tide is set in the Sunderbans, an island in the Bay of Bengal which isn't recently delightful yet additionally intriguing. For pilgrims, the Sunderbans offers to a great degree eccentric and unreliable life." By dramatizing the encounter between bourgeois characters and the traumatic history of people inhabiting the Sundarbans region of Bengal, Ghosh suggests that an unreconstructed cosmopolitanism is incapable of addressing social injustices" says Terri Tomsky in his article when talking about the novel.

The Hungry Tide is a deliberate attempt to provoke readers to think in fresh ways about the role and meaning of place in fictional and nonfictional narratives - both in narratological and ideological terms. In short, Ghosh's depiction of the Sundarbans exposes the limits of conceiving character and setting as distinct (and opposed) categories (Fletcher pg 5)

Distress and ousting are consistent dangers and assaults by tigers are generally normal. Tidal surges demolish the dependability of life on the island with no notice. AmitavGhosh's The Hungry Tide always talks about the contention amongst man and nature with regards to the Sundarbans in India and Bangladesh. The novel mirrors the contentions between the occupants and the oceanic and untamed life of the Sunderbans.

On all levels of the story, in fact, the forces of the global interact powerfully with the local, be that in ecological, economic, or cultural terms. And, in the end, an engaged globalism and an engaged localism emerge as coconstitutive, and are posited together opposite the force of destructive national and regional politics (AlexaWeik, Pg 121)

There have been various instances in the novel which cite the relevance and dependence upon nature for livelihood. The entire scene is set in the Sundarbans which is an area which dwells in costal biodiversity. "Ecology found its voice by studying the properties of species, their distribution across space, and their adaptive discourse in time" says William Howarth in the Ecocriticism Reader. This stays in tandem with the life lived by the characters in the story. Piyali Roy by profession is a Marine Biologist who lives a life by studying the intricacies in the life of the renowned Irrawaddy Dolphins. AmitavGhosh has shown this character as a person of strength and grit to withstand the problems faced by man i.e. the government and so on. She has the characters of an Ecofeminist. Where she earns the name of being a feminist by her ideals and her very close connection and desire to study this particular breed is depicted in the novel. As Karen J Warren states in her work, she claims that Women and the environment have a closer walk together. As they have close connection with nature, they have their pursuits too in accordance to their walk with nature. Piyali Roy as a cetologist helps in the understanding marine animals and others. In the end the connection established between her and the environment is evident in the text.

There are no borders here to divide fresh water from salt, river from sea. The tides reach as far as three hundred kilometers inland and every day thousands of acres of forest disappear underwater only to re-emerge hours later. The currents are so powerful as to reshape the islands almost daily some days the water tears away entire promontories and peninsulas; at other times it throws up new shelves and sandbanks where there were none before. (13)

\section{CONCLUSION}

India is a country which is rich in biodiversity. The country is rich in Flora and Fauna and hence it is seen in the works of writers. This collage of ideas and thoughts sync well with the literature. In accordance to that, literature has come to grow alongside with such scenic and aesthetic descriptions in the works of Indian Authors. Hungry Tide is 
one such novel which has immense amounts of such literature in correlation to that. The protagonist itself studies nature and the tale tapers on that very note. Piyali Roy tries to do research and can be seen as an Eco Feminist based on this work. Nature is seen as a provider in her household too, despite not being the traditional provider, it does provide in a different way. The Novel is filled with Ecocritical elements and stands as literary elements which add flavour and beauty to the novel by broadcasting the relationship between man and nature. This is highlighted in the novel and the plans and ideas that help nature and man coexist can be seen in the novel.

The harmonious balance between man and nature is meticulously explained through the novel. The fact of coexistence between man and nature is inscribed through this novel. It also paved way for man to understand that there is no life possible without establishing relationship between man and nature. Mother earth has infinitely generated various problem, which is an inductive reminder to safe guard the earth. Literature acts as a tool and a medium to link nature and man and also strives for effective commencement of actions to mankind. Ghosh has remarkably included the elements of caution through every character deployed in the novel. Ecology has proved to be a striving force throughout the novel which alters the way of life people lived in the past and also featured in the present. There is fear instilled in Moyna, who is depicted to be the one of the bravest characters with will power, fears nature to safe guard her son's life. This is the strongest reinforcement from nature against all odds to win man.

\section{BIBLIOGRAPHY}

1. Anand, Divya. "Words on Water: Nature and Agency in Amitav Ghosh." Concentric: Literary and Cultural Studies 34.1 (2008): 21-44.

2. Fletcher, Lisa M. "Reading the Postcolonial Island in Amitav Ghosh's The Hungry Tide." Island Studies Journal 6.1 (2011): 3-16.

3. Ghosh, Amitav. The Hungry Tide. London: HarperCollins, 2004. Print.

4. Glotfelty, Cheryll and Harold Fromm (Eds). The Ecocriticism Reader: Landmarks in Literary Ecology. Athens and London: University of Georgia, 1996.

5. Goh, Robbie BH. "The Overseas Indian and the political economy of the body in Aravind Adiga's The White Tiger and Amitav Ghosh's The Hungry Tide." The Journal of Commonwealth Literature 47.3 (2012): 341356.

6. Gurr, Jens Martin. "Emplotting an Ecosystem: Amitav Ghosh's The Hungry Tide and the Question of Form in Ecocriticism." Cross/Cultures 121 (2010): 69.

7. Howarth, William. "Some principles of ecocriticism." The Ecocriticism Reader: Landmarks in literary ecology (1996): 69-91.

8. Warren, Karen, Karen J. Warren, and Nisvan Erkal, eds. Ecofeminism: Women, culture, nature. Indiana University Press, 1997.

9. Mukherjee, Pablo. "Surfing The Second Wave: Amitav Ghosh's The Hungry Tide." Literature and Globalization: A Reader. Ed. Liam Connell and Nicky Marsh. London and New York: Routledge (2011).

10. Nayar, Pramod K. "The Postcolonial Uncanny; The Politics of Dispossession in Amitav Ghosh's 'The Hungry Tide."' College Literature, vol. 37, no. 4, 2010 , pp. 88-119. JSTOR, www.jstor.org/stable/27917766.
11. Sankaran, Chitra, ed. History, Narrative, and Testimony in Amitav Ghosh's Fiction. SUNY Press, 2012.

12. Tomsky, Terri. "Amitav Ghosh's Anxious Witnessing and the Ethics of Action in The Hungry Tide." The Journal of Commonwealth Literature, vol. 44, no. 1, Mar. 2009, pp. 53-65, doi:10.1177/0021989408101651

13. Weik, Alexa. "The home, the tide, and the world: ecocosmopolitan encounters in Amitav Ghosh's The Hungry Tide." Journal of Commonwealth and Postcolonial Studies Vols 13.14.1 (2006): 2006-2007. 